Articles should deal with topics applicable to the broad field of program evaluation. Articles may focus on evaluation methods, theory, practice, or findings. In all cases, implications for practicing evaluators should be clearly identified. Examples of contributions include, but are not limited to, reviews of new developments in evaluation, descriptions of a current evaluation study, critical reviews of some area of evaluation practice, and presentations of important new techniques. Manuscripts should follow APA format for references and style. Length per se is not a criterion in evaluating submissions.

\title{
Presidential Address: On Mainstreaming Evaluation
}

\author{
JAMES R. SANDERS
}

\begin{abstract}
The practice of evaluation in organizations continues to be limited by perceptions that evaluation is a marginal activity. Arguments demonstrating the importance of evaluation have been ineffective in moving most organizations toward integrating evaluation into their daily routines. A multifaceted approach to making evaluation a part of organizational culture is proposed. It includes using allies, examples, models, research, process guides, and trainers/developers. This article is based on The Presidential Address given by Dr. James R. Sanders at the 2001 Annual Meeting of the American Evaluation Association (AEA) in St. Louis, MO. The theme for the conference was "Mainstreaming Evaluation."
\end{abstract}

\section{ON MAINSTREAMING EVALUATION}

I wonder. I wonder why in 1973 Blaine Worthen and I opened our book on evaluation (Worthen \& Sanders, 1973) with the observation that evaluation is one of the most widely discussed but little used processes in today's systems, and yet today, almost 30 years later, I continue with

James R. Sanders • Professor Emeritus of Educational Studies, The Evaluation Center, Western Michigan University, 401 B Ellsworth Hall, Kalamazoo, MI 49008, USA; Tel: (1) 616-385-5895; Fax: (1) 616-387-5923; E-mail: james.sanders @wmich.edu.

American Journal of Evaluation, Vol. 23, No. 3, 2002, pp. 253-259. All rights of reproduction in any form reserved. ISSN: 1098-2140 @ 2002 by American Evaluation Association. Published by Elsevier Science Inc. All rights reserved. 
the uneasiness that I felt back then. Has anything changed since then? I should hope so. But has evaluation become second nature? I don't think so. This brings me to think about the need to mainstream evaluation.

\section{Mainstreaming Defined}

Mainstreaming refers to the process of making evaluation an integral part of an organization's everyday operations. Instead of being put aside in the margins of work, evaluation becomes a routine part of the organization's work ethic if it is mainstreamed. It is part of the culture and job responsibilities at all levels of the organization.

The role of evaluation in most organizations, including community agencies, schools, government agencies, and businesses, has been marginal up to now. It is ignored, given lip service, delegated to external consultants, or left to autocratic leaders. Consequently, change is often slow to take place and organizations fail to be as effective as they might be (Gray, 1998). The influence of evaluation as a process and as a profession has been limited.

There are many ways that we can talk about evaluation use. They have received a lot of attention in the evaluation literature over the past 30 years.

For example, considerable attention has been directed toward institutionalizing evaluation (Stufflebeam, 1997) - a commitment by organizations to evaluation. Most organizations in every sector have made this commitment, through accreditation, audits, policy statements, guides, assigned personnel, or some other tangible evidence of investment in evaluation. But, does institutionalization guarantee sustainable use and a widespread valuing of evaluation throughout the organization? I don't think so. Institutionalization does not necessarily lead to evaluation use or to valuing evaluation throughout the organization. In my experience evaluation has often been sporadic and highly variable in intensity depending on the leadership of the moment in the organization, external pressures for evaluation, accreditation cycles, and other environmental factors. For example, schools in the United States have institutionalized accreditation, a commitment to evaluation, yet one would be hard pressed to find examples of sustained and continuous evaluation use associated with the institutionalization of accreditation.

Then there is capacity building in evaluation, the theme of last year's AEA Annual Meeting. I would distinguished between the goal of evaluation capacity building, which includes an array of practices directed toward improving the quality of evaluation and its use in an organization, and mainstreaming evaluation, which is moving evaluation to the forefront of organizational thinking and behavior. Evaluation capacity building may, or may not, address the goal of mainstreaming evaluation. We may put more resources into evaluation (capacity building), but fail to move evaluation into the culture of the organization (mainstreaming). As one Ford Motor Company executive recently put it:

We don't have a quality problem at Ford, but it's not where we want it to be ... We're trying to make this [the company's quality control system] not just a program, and that takes time (USA Today, July 11, 2001, p. 3B).

To clarify the distinctions among the concepts of mainstreaming, institutionalizing, and building capacity in evaluation within organizations, see Table 1.

Mainstreaming evaluation in organizations depends in part on capacity building in evaluation, but it also depends on evaluation being internalized as a value throughout the organization and on an infrastructure that supports and maintains evaluation. Institutionalizing organizational structure, policies, procedures (e.g., accreditation), and systems (e.g., quality control) 
TABLE 1.

A Comparison of the Concepts of Mainstreaming, Institutionalizing, and Building Capacity in Evaluation in Organizations

\begin{tabular}{|c|c|c|c|}
\hline & Timing & $\begin{array}{c}\text { Tie to Organizational } \\
\text { Culture }\end{array}$ & $\begin{array}{c}\text { Tie to Organizational } \\
\text { Development }\end{array}$ \\
\hline Mainstreaming & Continuous & $\begin{array}{l}\text { Valued throughout; } \\
\text { accepted behavior }\end{array}$ & $\begin{array}{l}\text { The means to } \\
\text { organizational } \\
\text { improvement }\end{array}$ \\
\hline Institutionalizing & Periodic or episodic & $\begin{array}{l}\text { Often imposed; } \\
\text { necessary, but not } \\
\text { sufficient for } \\
\text { mainstreaming }\end{array}$ & $\begin{array}{l}\text { Leads to periodic or } \\
\text { episodic organizational } \\
\text { review; necessary but not } \\
\text { sufficient for improving } \\
\text { organizations }\end{array}$ \\
\hline Building capacity & Episodic or discrete & $\begin{array}{l}\text { Often imposed; } \\
\text { necessary, but not } \\
\text { sufficient for } \\
\text { mainstreaming }\end{array}$ & $\begin{array}{l}\text { Leads to episodic } \\
\text { organizational } \\
\text { improvement; necessary, } \\
\text { but not sufficient for } \\
\text { improving organizations }\end{array}$ \\
\hline
\end{tabular}

can contribute to organizational improvement, but will not be effective if they are not in the mainstream of organizational life. I believe these distinctions to be important in getting the best use out of evaluations in organizations.

In recent years thinking about evaluation use has evolved beyond how discrete evaluation findings are used. Current thinking about evaluation use is focused on the use of the evaluation process, including communities of practice (Wenger, 1998), to bring about organizational improvements (Caracelli \& Preskill, 2000; Ryan \& DeStefano, 2000). This is closer than previous discussions of evaluation use to what I mean by mainstreaming evaluation. That is, organizational improvement is brought about by many minds working together, sharing information, toward a common goal-helping the organization to continue to become more effective.

Many questions can be generated from the one I started with, "Why hasn't evaluation become second nature?" Derivative questions include:

- Where is evaluation mainstreamed?

- How did that happen?

- What difference did it make?

- What are the barriers to mainstreaming evaluation?

- What will it take to address each barrier?

- What role can AEA play in mainstreaming evaluation?

- Are there settings in which mainstreaming evaluation is not desirable?

There are also questions about how mainstreaming relates to other developments in evaluation. Is mainstreaming the same as empowerment evaluation? I would say it is related but the empowerment in mainstreaming comes from boards and CEOs and managers and union leaders and craft masters and consumers, and other exemplary leaders. Is mainstreaming linked with participatory evaluation? I would say yes, but again the energy behind evaluation is pervasive within the organization if evaluation has been mainstreamed. The hallmarks of mainstreaming 
are an organization whose culture values evaluation, whose practices make evaluation continuous, and whose history is of ongoing use of evaluations to improve the organization's effectiveness.

During the closing session of the 2001 AEA Conference, colleague Michael Patton noted that mainstreaming is as much about "them" (people who are not evaluation specialists) as it is about "us" (evaluation specialists). It is their values and their organizational behavior that I worry about most. Our role is to see that sound evaluations that help to assure that organizations are doing the right things, especially given complex contexts, are the evaluations that are being mainstreamed.

\section{The Organization Where Evaluation has Become Mainstreamed}

What does it look like? How can one tell if evaluation has been mainstreamed? I would look to see if the organization, as Schein (1992) puts it, has developed a consensus around the use of evaluation to help it move toward its goals (short term), mission (long term), and vision (the ultimate ideal). Figure 1, as I have described elsewhere (Sanders, 1994), captures this concept. That is, evaluation is seen as a means for learning, changing, and becoming more effective in moving toward the vision for the organization. Consensus, as used by Schein, implies many minds working together to achieve excellence as an organization. Consensus requires shared values, assumptions, and meanings (Schein, 1985).

Indicators that evaluation has been mainstreamed within an organization could include the following:

- Someone asking "how are you going to evaluate this?"

- Board members asking for evaluation findings for every program report.

- Evaluation appearing on the agenda of every staff meeting.

- Buyers asking for evaluation data from every sales agent.

- Clients being asked for evaluation that is then taken seriously by staff members.

- The CEO distributing a list of organizational values that includes continuous evaluation.

- Orientation training for new employees that includes their role in evaluating services, policies, and products.

- Using evaluation advocacy as a selection criteria when hiring new staff.

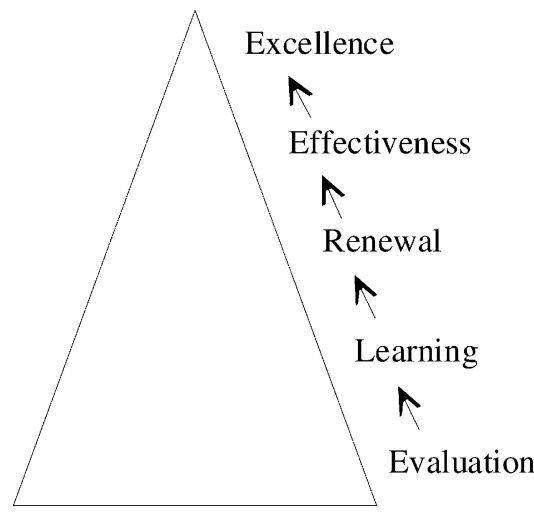

Figure 1. Role of Evaluation: Improve Practice. 
My experience tells me that for evaluation to be mainstreamed, evaluation must be developed as a core value. But, how do you develop evaluation as a core value in an organization? I would say it is a slow process that requires patience at all levels of the organization. Elsewhere (Sanders, 2001) I have proposed five stages in developing of evaluation as a core value, drawing from the work of Krathwohl, Bloom, and Masia (1964). The five stages are as follows:

1. Awareness - being aware of the importance of evaluation to the organization is developed.

2. Acquiescence and compliance - evaluation is done because it is required.

3. Obligation - a feeling of guilt when evaluation is absent or perfunctory is evident.

4. Desire-organization members ask for evaluation; enthusiasm and commitment are evident.

5. Leadership - true believers planning, organizing, and doing evaluation on their own initiative. Capacity and structure to support evaluation are evident.

Professional development, capacity building, policy and infrastructure development, hiring new employees who possess desired traits, modeling behavior, mentoring, and rewarding desired behavior are all ways to move through these stages.

The more widespread evaluation as a core value is within an organization, the more mainstreamed evaluation is likely to become. That is, as Figure 1 suggests, the more widespread evaluation is as a core value, the more evaluation will be done, which should lead to better understanding of the ways in which the organization functions (learning), which can identify ways to improve the organization (renewal), which should increase its effectiveness and move it ever closer to that elusive goal of excellence.

\section{What are the Costs of Not Mainstreaming Evaluation?}

Scriven (1991) suggests several costs of not mainstreaming evaluation:

- Bad products and services cost lives and health, destroy quality of life, and waste the resources of those who cannot afford waste.

- Justice is not served without evaluation of both programs and personnel.

- Needs will not be addressed without evaluation-based program direction.

- Ambiguity, prejudice, and mythology will continue without evaluation.

- Motivation and self-esteem that comes from evaluation will be missed without it.

How many publishers rush to market untested curricula? How many manufacturers only test their products out of fear of litigation? If it weren't for the FDA, how many pharmaceuticals would hit the market without adequate testing? Or spot checks of meat packers by the USDA? How many of our civil rights would be in jeopardy if it weren't for the ACLU or NAACP?

The trouble is, we can only regulate or monitor so much that comes out of organizations, and even then such regulation and monitoring can only be so effective. Most services and products go unmonitored. Put another way, external monitoring and evaluation is needed when internal evaluation is ineffective or nonexistent, that is, when evaluation has not been mainstreamed.

\section{What to Do?}

It all seems so overwhelming, but it doesn't need to be. Where do we begin? 
First, there are issues to be resolved and concepts to be clarified. Members of AEA should be working on these things. Do we want everyone to behave like evaluators? Wouldn't that take the fun out of organizational activity? - the creativity? - the spontaneity? - the serendipity? What would happen to chaos theory? Do we really want to impose our ways on our friends? ("With friends like us, ...") I believe there is a distinction to be made between valuing evaluation and being an evaluator. If all employees valued evaluation, the work of evaluators would surely be easier than it is now. I support the concept of "co-evaluators" in organizations that was developed by Gray (1998). This approach places an emphasis on mainstreaming evaluation as a means of developing organizational effectiveness and excellence.

Second, there is work to be done. Is it realistic to expect that a small group of evaluators can impact the cultures of organizations in the public, private, and civic sectors? I would say, if not AEA, then who will lead the way? But, we need:

- Allies (there are others who write about mainstreaming evaluation). ${ }^{1}$

- Examples (asset mapping to identify exemplary cases and to encourage them to spread their knowledge).

- Models (case examples to guide diverse organizations).

- Research (impact studies of mainstreaming evaluation to demonstrate what appears to be obvious).

- Process guides (how to mainstream evaluation in your organization).

- Trainer/developers (who will help organizations develop evaluation as a core value and develop evaluation leaders who will help organizations do sound evaluation).

It is a challenge, but I am convinced that the investment will result in demonstrable payoffs for organizations willing to develop an evaluation culture.

Will we ever get to the point where we will not need external monitoring, regulation, auditing, and evaluation? I think not, because we are human. There are those who would argue correctly that self-evaluation alone is inadequate because of its inherent bias. But, will organizations become more effective at what they do, move closer to excellence as they define it because they mainstreamed evaluation? I think so, although we should never abandon metaevaluation and external evaluations of important products and services that affect us all.

\section{ACKNOWLEDGMENTS}

This article is an expanded version of the Presidential Address presented at the Annual Meeting of the American Evaluation Association, St. Louis, MO, November 2001. The author would like to thank Drs. Michael Hendricks and Melvin Mark plus another reviewer who contributed insightful and very useful comments to guide the refinement of the ideas found in this article. Any shortcomings, however, must be attributed to the author.

\section{NOTE}

1. Peter Drucker, and the Peter F. Drucker Foundation for Nonprofit Management, has encouraged social sector organizations to engage in self-assessments (Drucker, 1999). Wadsworth (1997) encouraged even the smallest of human service organizations to use evaluation, and she has creatively demonstrated how they can make it work. Gray (1998) and her associates, Astrid Merget, Edward Weaver, and Rebecca 
Adamson, have shared ideas about how to mainstream evaluation in social sector organizations (see Adamson \& Weaver, 1998; Merget \& Weaver, 1998). Deming (1986) has demonstrated that worker involvement in continuous improvement can work to improve organizational effectiveness.

\section{REFERENCES}

Adamson, R., \& Weaver, E. T. (1998). Adapting the evaluation process to the organizational culture. In S. T. Gray (Ed.), Evaluation with power. San Francisco, CA: Jossey-Bass.

Caracelli, V., \& Preskill, H. (Eds.) (2000). The expanding scope of evaluation use. New directions for evaluation (Vol. 88). San Francisco, CA: Jossey-Bass.

Deming, W. (1986). Out of the crisis. Cambridge, MA: MIT Press.

Drucker, P. F. (1999). The Drucker Foundation self-assessment tool. San Francisco, CA: Jossey-Bass.

Gray, S. T. (1998). Making evaluation a useful management tool. In S. T. Gray (Ed.), Evaluation with power. San Francisco, CA: Jossey-Bass.

Krathwohl, D. R., Bloom, B. S., \& Masia, B. B. (1964). Taxonomy of educational objectives: Handbook II: Affective domain. New York: David McKay.

Merget, A. E., \& Weaver, E. T. (1998). Organizational behavior and policy. In S. T. Gray (Ed.), Evaluation with power. San Francisco, CA: Jossey-Bass.

Ryan, K. E., \& DeStefano, L. (Eds.) (2000). Evaluation as a democratic process: Promoting inclusion, dialogue, and deliberation. New directions for evaluation (Vol. 85). San Francisco, CA: Jossey-Bass.

Sanders, J. R. (1994). Using evaluation to achieve your mission. Presentation at the Colorado Association of Nonprofit Organizations Annual Conference, Denver, CO.

Sanders, J. R. (2001). A vision for evaluation. American Journal of Evaluation, 22, 363-366.

Schein, E. (1985). Organizational culture and leadership: A dynamic view. San Francisco, CA: Jossey-Bass.

Schein, E. (1992). Organizational culture and leadership (2nd ed.). San Francisco, CA: Jossey-Bass.

Scriven, M. (1991). Evaluation thesaurus (4th ed.). Thousand Oaks, CA: Sage.

Stufflebeam, D. L. (1997). Strategies for institutionalizing evaluation: Revisited. Kalamazoo, MI: Western Michigan University Evaluation Center.

USA Today, July 11, 2001, p. 3B.

Wadsworth, Y. (1997). Everyday evaluation on the run. St. Leonards, NSW, Australia: Allen and Unwin.

Wenger, E. C. (1998). Communities of practice: Learning, meaning, and identity. Cambridge, UK: Cambridge University Press.

Worthen, B. R., \& Sanders, J. R. (1973). Educational evaluation: Theory and practice. New York: Wadsworth. 